\title{
BIBASIC SEQUENCES AND NORMING BASIC SEQUENCES
}

BY

\section{WILLIAM J. DAVIS, DAVID W. DEAN AND BOR-LUH LIN $\left({ }^{1}\right)$}

ABSTRACT. It is shown that every infinite dimensional Banach space $X$ contains a basic sequence $\left(x_{n}\right)$ having biorthogonal functionals $\left(f_{n}\right) \subset X^{*}$ such that $\left(f_{n}\right)$ is also basic. If $\left[f_{n}^{n}\right]$ norms $\left[x_{n}\right]$ then $\left(f_{n}\right)$ is necessarily basic. If $\left[f_{n}\right]$ norms $\left[x_{n}\right]$ then $\left[x_{n}\right]$ norms $\left[f_{n}\right]$. In order that $\left[f_{n}\right]$ norms $\left[x_{n}\right]$ it is necessary and sufficient that the operators $S_{n} x=\Sigma_{1}^{n} f_{i}(x) x_{i}$ be uniformly bounded. If $\left[f_{n}\right]$ norms $\left[x_{n}\right]$ then $X^{*}$ has a complemented subspace isomorphic to $\left[x_{n}\right]^{*}$. Examples are given to show that $\left(f_{n}\right)$ need not be basic and, if $\left(f_{n}\right)$ is basic, still $\left[f_{n}\right]$ need not norm $\left[x_{n}\right]$.

0 . Notation, definitions and introduction. In this paper, we let $E$ denote a Banach space. $E^{*}$ is the Banach space of all continuous linear functionals on E. If $U$ is a subspace of $E$, then $U^{\perp}=\left\{f \in E^{*}: f(x)=0\right.$ for all $x$ in $\left.U\right\}$. Similarly, if $V$ is a subspace of $E^{*}$, then $V_{\perp}=\{x \in E: f(x)=0$ for all $f$ in $V\}$. Let $f$ be a mapping on $E$ and $U$ be a subset of $E$, then $\left.f\right|_{U}$ is the restriction of $f$ to $U$. In particular, if $f \in E^{*}$ and $\left(x_{n}\right)$ is a sequence in $E$, then $\|f\|_{n}=$ $\left\|\left.f\right|_{\left[x_{n}+1, x_{n}+2, \ldots\right]}\right\|=\sup \left\{|f(x)|^{n}: x \in\left[x_{n+1}, x_{n+2}, \cdots\right],\|x\|=1\right\}$. Let $\left(x_{n}\right) \subset E$, then $\left[x_{n}\right]$ is the closed linear subspace spanned by $\left(x_{n}\right)$ and $\operatorname{span}\left(x_{n}\right)$ is the linear subspace spanned by $\left(x_{n}\right)$. For other notations and terminology concerning basic sequences, we refer to the book of I. Singer [21].

The concept of a norming set or norming $M$-basis or norming basic sequence in a Banach space has been studied by several authors (e.g. [2], [4], [9], [12]) because the existence of such systems implies much about the structure of the space.

If $U$ is a subspace of a Banach space $E$ and if $V$ is a subspace of $E^{*}$ say that $U$ norms $V$ if there is a $C>0$ such that

$$
\sup \{f(x): x \in U,\|x\| \leq 1\} \geq C\|f\|
$$

for every $f$ in $V$ (that is, $\left\|\left.f\right|_{U}\right\| \geq C\|f\|$ for all $f$ in $V$ ). The largest $C$ satisfying the above inequality is called the characteristic of $U$ over $V$. Again, if $U$

Received by the editors June 28, 1971.

AMS (MOS) subject classifications (1970). Primary 46B10, 46B15.

Key words and phrases. Basis, Markushevich basis, reflexivity, projection, complemented subspace, pseudo-reflexive space.

(1) The author was on leave from the University of Iowa. 
is a subspace of $E$ and $V$ is a subspace of $E^{*}$ say that $V$ norms $U$ if $V$ norms the natural embedding of $U$ in $E^{* *}$.

Let $\left(x_{n}\right)$ be a sequence in a Banach space $E$ and $\left(f_{n}\right)$ be a sequence in $E^{*}$. Say that $\left(x_{n} ; f_{n}\right)$ is a bibasic system in $E$ if it is a biorthogonal system and both $\left(x_{n}\right)$ and $\left(f_{n}\right)$ are basic in $E, E^{*}$ respectively. We show that every Banach space contains a bibasic system $\left(x_{n} ; f_{n}\right)$ such that $\sup _{n}\left\|x_{n}\right\| \cdot\left\|f_{n}\right\|<+\infty$.

If $\left(x_{n} ; f_{n}\right)$ is a basis system for $X$ (i.e., $\left[x_{n}\right]=X$ and $\left(x_{n}\right)$ is basic), then $\left(f_{n}\right)$ is basic and $\left[f_{n}\right]$ norms $\left[x_{n}\right]$. It is seen by way of examples that $\left(x_{n}\right)$ basic does not promise that $\left(f_{n}\right)$ is basic and if $\left(x_{n} ; f_{n}\right)$ is bibasic we cannot conclude that $\left[f_{n}\right]$ norms $\left[x_{n}\right]$.

Say that a basic sequence $\left(x_{n}\right)$ is shrinking in a Banach space $E$ if $\lim _{n \rightarrow \infty}\left\|\left.f\right|_{\left[x_{n+1}, x_{n+2}, \ldots\right]}\right\|=0$ for every $f$ in $E^{*}$ and that a basic sequence $\left(f_{n}\right)$ is boundedly complete in $E^{*}$ if, whenever $\left(\alpha_{n}\right)$ is a sequence such that $\left\{\left\|\sum_{i=1}^{n} a_{i} f_{i}\right\|\right\}_{n=1,2, \ldots}$ is bounded, one has that $\left\{\sum_{i=1}^{n} a_{i} f_{i}\right\}_{n=1,2, \ldots \text { con- }}$ verges [21]. We shall see in $\$ 3$ that, if $\left(x_{n}\right)$ is shrinking and if $\left[f_{n}\right]$ norms $\left[x_{n}\right]$, then there is a natural projection of $E^{* *}$ onto a subspace isomorphic to $\left[x_{n}\right]^{* *}$.

If $\left(x_{n} ; f_{n}\right)$ is a biorthogonal system with $\left(x_{n}\right) \subset E$ and $\left(f_{n}\right) \subset E^{*}$, the following questions arise in a natural way.

1. If $\left(x_{n}\right)$ is a basic sequence, must $\left(f_{n}\right)$ be basic? Indeed, if $\left(x_{n}\right)$ is a basis for all of $E$, the answer is yes [21], but if $\left[x_{n}\right]$ is a proper subspace we shall see that the answer is no.

2. If $\left(x_{n}\right)$ and $\left(f_{n}\right)$ are both basic, must $\left(f_{n}\right)$ be equivalent to the coefficient functionals $\left(\phi_{n}\right) \subset\left[x_{n}\right]^{*}$ ? We shall see in $\$ 3$ that this question has an affirmative solution if and only if $\left[f_{n}\right]$ norms $\left[x_{n}\right]$. Does a bibasic system with $\left\|x_{n}\right\|\left\|f_{n}\right\| \leq M<\infty$ for all $n$ have $\left[f_{n}\right]$ norming $\left[x_{n}\right]$ ? We show that both have negative solutions below.

3. Suppose that $\left(x_{n} ; f_{n}\right)$ is a bibasic system and that $\left(x_{n}\right)$ is shrinking (resp., boundedly complete); is $\left(f_{n}\right)$ boundedly complete (resp. shrinking)? Once again we shall show by examples that this question has a negative answer.

The examples of $\S 1$ are the motivation for the rest of this paper. The remainder of the paper is a study of conditions that yield positive answers to some of the questions above. The structure of the space is then explored in light of these conditions.

In $\$ 2$ we show that bibasic systems $\left(x_{n} ; f_{n}\right)$ exist in every infinite dimensional Banach $E$ space and that they can always be chosen with $\left(f_{n}\right)$ failing to norm $\left(x_{n}\right)$. If $E^{*}$ is separable the system may be chosen so that $\left(x_{n}\right)$ is shrinking and $\left(f_{n}\right)$ boundedly complete. In $\$ 3$ norming subspaces are studied and the results applied to norming bibasic systems. In particular, it is shown that $\left[f_{n}\right]$ norms $\left[x_{n}\right]$ if and only if $\left[x_{n}\right]$ norms $\left[f_{n}\right]$. Finally in $\$ 4$ the theorem that $\left[f_{n}\right]$ 
norms $\left[x_{n}\right]$ if and only if the operators $S_{n} x=\Sigma_{1}^{n} f_{i}(x) x_{i}$ are uniformly bounded is proved. In this case $\left[x_{n}\right]^{*}$ is naturally embedded as a complemented subspace of $E^{*}$ (Theorem 5 below).

1. Examples.

Example 1. Let $\mathbf{R}$ denote the reals and in $l_{2} \oplus \mathbf{R}$, let $x_{n}=\left(\delta_{n}, 0\right), f_{n}=$ $\left(\delta_{n}, 1\right)$. Then $\left(x_{n} ; f_{n}\right)$ is a biorthogonal system with $\sup _{n}\left\|x_{n}\right\| \cdot\left\|f_{n}\right\|<\infty$ and $\left(x_{n}\right)$ basic but $\left(f_{n}\right)$ is not basic:

$$
\left\|\sum_{j=1}^{n} f_{j}\right\|^{2}=\left\|\left(\sum_{j=1}^{n} \delta_{j}, n\right)\right\|^{2}=n+n^{2}
$$

but

$$
\left\|\sum_{i=1}^{n} f_{i}-\sum_{i=n+1}^{2 n} f_{i}\right\|^{2}=\left\|\left(\sum_{j=1}^{n} \delta_{j}-\sum_{j=n+1}^{2 n} \delta_{j}, 0\right)\right\|^{2}=2 n .
$$

Thus,

$$
\left\|\sum_{i=1}^{n} f_{i}-\sum_{i=n+1}^{2 n} f_{i}\right\| /\left\|\sum_{i=1}^{n} f_{i}\right\|=\left(\frac{2}{n+1}\right)^{1 / 2} \rightarrow 0 \quad \text { as } n \rightarrow \infty .
$$

Thus the natural projections of $\left[f_{n}\right]$ onto $\left[f_{1}, \cdots, f_{k}\right]$ fail to be uniformly bounded, so $\left(f_{n}\right)$ cannot be basic. Thus, we have the negative solution to the first question.

Example 2. Let $\left(e_{n}\right)$ denote the standard unit vector basis in $l_{p}(1<p<$ $q<\infty)$ and $\left(\epsilon_{n}\right)$ the unit vector basis in $l_{q}$. Let $1 / p+1 / p^{\prime}=1=1 / q+1 / q^{\prime}$, and let $\left(b_{n}\right)$ (resp. $\left(\eta_{n}\right)$ ) denote the standard unit vector basis in $l_{p}$, (resp. $l_{q}{ }^{\prime}$ ). Now, in $l_{p} \oplus l_{q}$ let $x_{n}=\left(e_{n}, 0\right)$ and in $\left(l_{p} \oplus l_{q}\right)^{*}$ let $f_{n}=\left(b_{n}, \eta_{n}\right)$ so that $\left(x_{n}, f_{n}\right)$ is a bounded bibasic system. Since $p^{\prime}>q^{\prime}$ it is easy to see that $\left(f_{n}\right)$ is equivalent to $\left(\eta_{n}\right)$. It can be computed directly, but follows immediately from Remark 3 below, that $\left[f_{n}\right]$ fails to norm $\left[x_{n}\right]$. This answers question 2.

Remark 1. Let $\left(x_{n} ; f_{n}\right)$ and $\left(y_{n} ; g_{n}\right)$ be basis systems in Banach spaces $X$ and $Y$, respectively. In $X \oplus Y$ let $z_{n}=\left(x_{n}, y_{n}\right)$ and suppose that $\left(x_{n}\right)$ and $\left(y_{n}\right)$ are not equivalent. Then either $\left(z_{n}\right)$ fails to be equivalent to $\left(x_{n}\right)$ or to $\left(y_{n}\right)$.. In the first case let $b_{n}=\left(f_{n}, 0\right)$, so that by Remark 3 below, [ $\left.b_{n}\right]$ cannot norm $\left[z_{n}\right]$.

Example 3. In $c_{0}$ denote the standard unit vector basis by $\left(e_{n}\right)$ and in $l_{1}^{n}$ let the standard unit vector basis be $\left(b_{n}\right)$. In $c_{0} \oplus c_{0}$ let $x_{n}=\left(e_{n}, e_{1}+e_{2}+\cdots\right.$ $\left.+e_{n}\right)$ and in $l_{1} \oplus l_{1}=\left(c_{0} \oplus c_{0}\right)^{*}$ let $f_{n}=\left(b_{n}, 0\right)$. Then $\left(x_{n} ; f_{n}\right)$ is bounded bibasic and $\left(f_{n}\right)$ is boundedly complete. However, $\left(x_{n}\right)$ is not shrinking since, letting $g=\sum 2^{-n}\left(0, b_{n}\right)$, we have $g\left(x_{k}\right)=\sum_{j=1}^{k} 2^{-j} \rightarrow 1$. From this we see that the restriction of $g$ to $\left[x_{n+1}, x_{n+2}, \cdots\right]$ has norm $=1$ for each $n$ which forces $\left(x_{n}\right)$ to be nonshrinking. 
From this example we conclude that for $\left(x_{n} ; f_{n}\right)$ bibasic, $\left(f_{n}\right)$ boundedly complete does not imply that $\left(x_{n}\right)$ is shrinking. By interchanging the roles of $\left(x_{n}\right)$ and $\left(f_{n}\right)$ in the above, we also see that $\left(x_{n}\right)$ boundedly complete does not force $\left(f_{n}\right)$ to be shrinking. This gives the negative solution to half of Question 3 above.

Example 4. In $c_{0}$ let the unit vector basis be $\left(e_{n}\right)$; in $l_{1},\left(b_{n}\right)$; in $l_{2},\left(\delta_{n}\right)$. In $c_{0} \oplus l_{2}$, let $x_{n}=\left(e_{n}, 2^{-n} \delta_{n}\right), f_{n}=\left(0,2^{n} \delta_{n}\right)$. Again, it is easy to see that $\left(x_{n} ; f_{n}\right)$ is bibasic. Further $\left[f_{n}\right]=(0) \oplus l_{2}$, so $\left(f_{n}\right)$ is shrinking. However, $\sum a_{n} x_{n}$ converges if and only if $a_{n} \rightarrow 0$, that is $\left(x_{n}\right)$ is equivalent to the standard unit vector basis of $\left(c_{0}\right)$. It is, therefore, not boundedly complete.

With this we see that $\left(f_{n}\right)$ may be shrinking without having $\left(x_{n}\right)$ boundedly complete. Once again, we may interchange the roles of $\left(x_{n}\right)$ and $\left(f_{n}\right)$ to see that $\left(x_{n}\right)$ may be shrinking and have $\left(f_{n}\right)$ fail to be boundedly complete. This completes the negative solution to question 3.

From Theorem 4 of [2] as well as Remark 3 below it would follow that every Banach space $E$ with basis would have a direct sum decomposition $E=F \oplus G$, with both $F$ and $G$ infinite dimensional, if for every basic system $\left(x_{n} ; f_{n}\right)$ there is an infinite-coinfinite $\left(n_{k}\right)$ such that $\left(x_{n_{k}}, f_{n_{k}}\right)$ is a norming bibasic system.

The next example shows that this is not in general possible. (2)

The reader will see that the basis $\left(x_{n}\right)$ has a block basic subsequence $\left(\left(x_{n+1}-x_{n}\right)\right)$ which is unconditional.

Example 5. In $c_{0}$ let $x_{n}=e_{1}+\cdots+e_{n}$ and $f_{n}=b_{n}-b_{n+1} ; n=1,2, \cdots$ For every subsequence $\left(n_{k}\right)$ of the integers, $\left(x_{n_{k}}\right)$ is equivalent to $\left(x_{n}\right)$, but if $\left(n_{k}^{\prime}\right)$ is infinite, $\left(f_{n_{k}}\right)$ cannot be equivalent to $\left(f_{n}\right)$ : Let $p_{1}<p_{2}<\ldots$ be chosen so that, for each $j, p_{j} \in\left(n_{k}\right)$ but $p_{j+1} \notin\left(n_{k}\right)$. Set $p_{0}=0$ for convenience. Let $l_{j}=\left[p_{j-1}+1, \cdots, p_{j}\right] \cap\left(n_{k}\right)$ and $F_{j}=\left[f_{i} \mid i \in I_{j}\right]$. Then $\left(\Sigma F_{j}\right)_{l_{1}}$ is a natural unconditional decomposition for $\left[f_{n_{k}}\right]$, but $\left[f_{n}\right]$ admits no such (natural) decomposition.

2. Existence of bibasic systems. Here we see that every infinite dimensional Banach space has a bounded bibasic system. We also see that every space has such a system which fails to be norming. The first theorem is a generalization of the technique for constructing basic sequences which is due to Day, Gelbaum and Mazur (see, e.g. [1], [6], [9], [14], [15]). A shorter proof quoting results from [1] and [14] is possible, but this proof allows the extension of Remark 5 below.

Theorem 1. Every infinite dimensional Banach space has a bounded bibasic system.

Proof. Let $E$ be the space, $\left\|x_{1}\right\|=\left\|f_{1}\right\|=f_{1}\left(x_{1}\right)=1$. Choose $z_{1}, \cdots, z_{q_{1}}$

(2) The authors wish to thank A. Pełczyński for pointing out this fact for us. 
in $E$ so that $U_{1}=\left[x_{1}, z_{1}, \cdots, z_{q_{1}}\right]$ has the property that

$$
1 / 2\|f\|<\sup \left\{\mathrm{f}(u):\|u\|=1, u \in U_{1}\right\} .
$$

Next choose $g_{1}, \cdots, g_{p_{1}}$ in $E^{*}$ such that $V_{1}=\left[f_{1}, g_{1}, \cdots, g_{p_{1}}\right]$ has the property that

$$
1 / 2\|u\|<\sup \left\{b(u):\|b\|=1, b \in V_{1}\right\} .
$$

Now choose $x_{2}$ to be any norm 1 element in $\left(V_{1}\right)_{\perp}$ in $E$ so that (1) forces $d\left(x_{2}, U_{1}\right)>1 / 3$. The Hahn-Banach theorem now guarantees the existence of $f_{2}$ in $E^{*}$ with $\left\|f_{2}\right\| \leq 3, f_{2}\left(x_{2}\right)=1$ and $f_{2}\left(U_{1}\right)=0$. (That is, $f_{2} \in U_{1}^{\perp}$.) We now notice that the natural projections of $U_{1} \oplus\left(V_{1}\right)_{\perp}$ onto $U_{1}$ and $\left[f_{1}\right] \oplus U_{1}^{\perp}$ onto $\left[f_{1}\right]$ have norm $\leq 2$. Now suppose we have $\left\{f_{1}, \cdots, f_{n}\right\},\left\{g_{1}, \cdots, g_{p_{n}}\right\},\left\{x_{1}, \cdots\right.$, $\left.x_{n}\right\}$ and $\left\{z_{1}, \cdots, z_{q_{n}}\right\}$ and $U_{n}=\left[x_{1}, \ldots, x_{n}, z_{1}, \cdots, z_{q_{n}}\right], V_{n}=\left[f_{1}, \cdots, f_{n}\right.$, $\left.g_{1}, \cdots, g_{p_{n}}\right]$ with the properties that, for $b$ in $\left[f_{1}, \cdots, f_{n}^{n}\right], x$ in $U_{n}$,

$$
\begin{aligned}
& 1 / 2\|b\| \leq \max \left\{b(u):\|u\|=1, u \in U_{n}\right\}, \\
& 1 / 2\|x\| \leq \max \left\{g(x):\|g\|=1, g \in V_{n}\right\} .
\end{aligned}
$$

(3) and (4) imply that the natural projections of $U_{n} \oplus\left(V_{n}\right)_{\perp}$ onto $U_{n}$ and $\left[f_{1}, \cdots\right.$, $\left.f_{n}\right] \oplus U_{n}^{\perp}$ onto $\left[f_{1}, \cdots, f_{n}\right]$ have norm $\leq 2$. Thus, if $x_{n+1}$ is any norm 1 element of $\left(V_{n}\right)_{\perp}, d\left(x_{n+1}, U_{n}\right) \geq 1 / 3$, so there is, by Hahn-Banach, $f_{n+1}$ of norm $\leq 3$ in $U_{n}^{\perp}$ such that $f_{n+1}\left(x_{n+1}\right)=1$. Now choose $z_{q_{n}+1}, \cdots, z_{q_{n+1}}$ so that $U_{n+1}$ satisfies (3) for $\left[f_{1}, \cdots, f_{n+1}\right]$. Next choose $g_{p_{n}+1}, \cdots, g_{p_{n+1}}$ so that (4) holds for $V_{n+1}$. The resulting system $\left(x_{n} ; f_{n}\right)$ is bounded and bibasic..

The previous result was obtained independently by W. Johnson and H. Rosenthal [8]. There they have also shown that if $E^{*}$ is separable, then $E^{*}$ contains a boundedly complete basic sequence. This corollary is, in a sense, dual to that result. On the other hand, it has been proved by Dean, Singer and Sternbach [3] that every Banach space with separable dual contains a shrinking basic sequence.

Corollary 1. If $E^{*}$ is separable then $E$ contains a bounded bibasic $\left(x_{n} ; f_{n}\right)$ for which $\left(x_{n}\right)$ is shrinking.

Proof. Let $\left(y_{n}, g_{n}\right)$ be a bounded bibasic sequence in $E$. Since $E^{*}$ is separable, a subsequence $\left(z_{k}\right)$ of $\left(y_{n}\right)$ is weakly Cauchy, say $z_{k}=y_{n_{k}}$. Set $b_{k}=$ $g_{n_{k}}$. Then $\left(z_{k}, b_{k}\right)$ is bounded bibasic. Let $\left(\omega_{i}\right)$ be dense in $E^{*}$ and $\epsilon_{k}>0$ with $\Sigma_{t=1}^{\infty} \epsilon_{k}<+\infty$. Choose $k_{j}, l_{j}$ such that $k_{j}<l_{j+1}<k_{j+1}, j=1,2, \ldots$, and $\left|\omega_{i}\left(z_{p}\right)-\omega_{i}\left(z_{q}\right)\right|<\epsilon_{j}$ for all $i \leq j$ and $p, q \geq l_{j}$.

Now, if $x_{j}=z_{k_{j}}-z_{l_{j}}$, then $\left(x_{j}, b_{k_{j}}\right)$ is bounded bibasic and if $x=$ $\sum_{j=m+1}^{\infty} \alpha_{j} x_{j}$ where $m \geq i,\|x\|=1$, then

$$
\left|\omega_{i}(x)\right| \leq \sum_{j=m+1}^{\infty}\left|\alpha_{j}\right| \epsilon_{j} \leq 2 K(K+1) \sum_{j=m+1}^{\infty} \epsilon_{j}
$$


where $K$ is the basis constant of $\left(x_{j}\right)$. Thus $\left\|\omega_{i} \mid\left[x_{m+1}, x_{m+2}, \cdots\right]\right\| \rightarrow 0$ as $m \rightarrow \infty$ for each $i$, so $\left(x_{j}\right)$ is shrinking.

Remark 2. In [8] it is shown that a bounded biorthogonal system $\left(x_{n} ; f_{n}\right)$ may be constructed so that $\left(f_{n}\right)$ is boundedly complete whenever $E^{*}$ is separable. Using the technique of Corollary 1 , one may find $\left(y_{n}, g_{n}\right)$ bounded bibasic with $\left(y_{n}\right)$ shrinking and $\left(g_{n}\right)$ boundedly complete whenever $E^{*}$ is separable.

Proposition 1. Every infinite dimensional Banach space has a bounded bibasic system $\left(z_{n}, b_{n}\right)$ with $\left[b_{n}\right]$ failing to norm $\left[z_{n}\right]$.

Proof. If $\left(z_{n}, b_{n}\right)$ is bounded bibasic, $\left[z_{n}\right] \subset E,\left(b_{n}\right) \subset E^{*}$ and if $\left(b_{n}\right)$ does not norm $\left(z_{n}\right)$ then we are done.

If $\left(b_{n}\right)$ does norm $\left(z_{n}\right)$ we use Theorem 5 below as follows. There is an isomorphism $Q$ of $\left[z_{n}\right]^{*}$ into $E^{*}$ such that $Q f(x)=f(x)$ for every $f$ in $\left[z_{n}\right]^{*}$ and $x$ in $\left[z_{n}\right]$. Let $\left(x_{n}\right)$ be a normalized conditional basis of $\left[z_{n}\right]$ with biorthogonal functionals $\left(f_{n}\right)$. If $\left(Q f_{n_{k}}\right)$ norms $\left(x_{n_{k}}\right)$ then $\left(f_{n_{k}}\right)$ in $\left[z_{n}\right]^{*}$ norms $\left(x_{n_{k}}\right)$ in $\left[z_{n}\right]$. Then, again by Theorem 5 below, the operators

$$
P_{k}(x)=\sum_{i=1}^{k} f_{n_{i}}(x) x_{n_{i}}
$$

are uniformly bounded on $\left[x_{n}\right]$. For $x=\Sigma \alpha_{i} x_{i}, \lim P_{k}(x)=\sum_{i=1}^{\infty} f_{n_{k}}(x) x_{n_{i}}$ exists and is a continuous projection onto $\left[x_{n_{i}}\right]$. If such a projection exists for every sequence $\left(x_{n_{i}}\right)$ (since $\lim _{k \rightarrow \infty} P_{k} x_{i}=\bigcap^{n_{i}}$ if $j \notin\left(n_{i}\right)$ ) then $\left(x_{n}\right)$ is unconditional. This contradiction shows that for some sequence $\left(x_{n_{k}}\right),\left(f_{n_{k}}\right)$ does not norm $\left(x_{n_{k}}\right)$ whence $\left(Q f_{n_{k}}\right)$ does not norm $\left(x_{n_{k}}\right)$. Q.E.D.

3. Norming subspaces. In [4], Dixmier showed that a total subspace $V$ of $E^{*}$ is norming if and only if $V^{\perp}+E$ is closed in $E^{* *}$. The first result of this section is a generalization of his result to the situation " $V \subset E^{*}$ norms $U \subset E$." The rest of the section is devoted to extending other known results concerning norming subspace to this situation and to the application of these to bibasic systems. For subspaces $U$ in $E$ and $V$ in $E^{*}$, say that $V$ is a total over $U$ if $V_{\perp} \cap U=\{0\}$. Similarly, say that $U$ is total over $V$ if $U^{\perp} \cap V=\{0\}$.

Theorem 2. Let $U$ be a subspace in $E$ and $V$ be a subspace in $E^{*}$. If IJ is total over $V$, then the following are equivalent:

(1) U norms $V$.

(2) $U^{\perp}+V$ is closed in $E^{*}$.

(3) The natural mapping from $V$ to $U^{*}$ is an isomorphism.

Proof. Let $I: U \rightarrow E$ be the embedding. Then $I^{*}$ is the natural mapping from $E^{*}$ onto $U^{*}$. Given $f$ in $V$, then 


$$
\left\|I^{*}\right\|=\inf _{g^{\in} V^{\perp}}\|f+g\|=\sup \{\|f(x) \mid: x \in U,\| x \|=1\} .
$$

Hence $U$ norms $V$ if and only if $I^{*}$ is an isomorphism. Thus (1) and (3) are equivalent.

By the closed graph theorem, $U^{\perp}+V$ is closed if and only if the natural projection from $U^{\perp}+V$ to $V$ is continuous which is equivalent to saying that there exists a $c>0$ such that $\inf _{g \in U^{\perp}}\|f+g\| \geq c\|f\|$ for all $f$ in $V$. Thus (2) and (3) are equivalent.

It is well known that every total subspace of the dual of a quasi-reflexive space (i.e. $E$ satisfies $\left.\operatorname{dim}\left(E^{* *} / E\right)<\infty\right)$ is norming ([17], [19]). Theorem 2 allows the following generalization of that result. Let $U$ be a quasi-reflexive subspace of a Banach space $E$ and let $V$ be a subspace in $E^{*}$ which is total over $U$. If $U$ norms $V$ then $V$ norms $U$.

A space $E$ is called pseudo-reflexive if $E^{*} \supset V$ such that the natural map of $E$ to $V^{*}$ is an isomorphism onto [20]. In [11], [20] it is shown that $E$ is pseudo-reflexive if $E^{*}$ contains a subspace $W$ which is minimal with respect to the property of being total over $E$.

Proposition 2. Let $U$ be a subspace in a Banach space E. If $V$ is a mini-mal subspace in $E^{*}$ with respect to the property of being total over $U$, then $V$ norms $U$ and $U$ is isomorphic onto $V^{*}$ under the natural mapping.

Proof. Suppose $V$ does not norm $U$. Then $V^{\perp}+U$ is not closed in $E^{* *}$. Thus $V^{\perp}$ is a quasi-complement of $U$ but not a complement in $\overline{V^{\perp}+U}$. Hence there exists a quasi-complement $A$ of $U$ in $\overline{V^{\perp}+U}$ such that $V^{\perp}$ is a proper subspace of $A$ [13]. Then $A_{\perp}$ is a proper subspace of $V$ which is total over $U$. Thus $V$ is not minimal.

Let $\phi: U \rightarrow V^{*}$ be the natural mapping, that is $\phi(x)(f)=f(x)$ for all $x$ in $U$ and $f$ in $V$. Since $V$ norms $U, \phi$ is an isomorphism on $U$. Given $v^{*} \neq 0$ in $V^{*}$, let $F=\left\{f \in V: v^{*}(f)=0\right\}$. Then $F$ is a proper subspace of $V$ and so is not total over $U$. Let $0 \neq x \in U$ such that $f(x)=0$ for all $f$ in $F$. Then $\phi(x)=a v$ * for some $a \neq 0$. Thus $\phi(U)=V^{*}$.

It is easy to see that if $W$ is a total nonnorming subspace of $E^{*}$, then $W$ must have infinite codimension in $E^{*}$ (this is immediate from the Dixmier characterization of norming mentioned above). In fact, let $U$ be a subspace of a Banach space $E$ and let $V$ be a subspace in $E^{*}$ which norms $U$. If $F$ is a subspace in $V$ with finite codimension and $F$ is total over $U$ then $F$ norms $U$.

The next proposition provides the key to the study of norming bibasic systems.

Proposition 3. Let $\left(x_{n} ; f_{n}\right)$ be a biorthogonal system in a Banach space E. Then $\left[x_{n}\right]$ norms $\left[f_{n}\right]$ if and only if $\left[f_{n}\right]+\left[x_{n}\right]^{\perp}$ is closed in $E^{*}$. If, in addition, 
that $\left(x_{n}\right)$ is basic, then $\left[x_{n}\right]$ norms $\left[f_{n}\right]$ implies that $\left[f_{n}\right]$ norms $\left[x_{n}\right]$.

Proof. The first statement is a direct consequence of Theorem 2. Suppose $\left[x_{n}\right]$ norms $\left[f_{n}\right]$. The natural mapping $I^{*}$ is an isomorphism from $\left[f_{n}\right]$ to $\left[x_{n}\right]^{*}$. Now $I^{*}\left[f_{n}\right]=\left[I^{*} f_{n}\right]$ is the coefficient space of $\left(x_{n}\right)$ in $\left[x_{n}\right]^{*}$. Thus $\left[I^{*} f_{n}\right]$ norms $\left[x_{n}\right]$ and $\left[f_{n}\right]$ norms $\left[x_{n}\right]$.

Remark 3. If, in Theorem 2, we let $U=\left[x_{n}\right]$ (resp. $\left[f_{n}\right]$ ) and $V=\left[f_{n}\right]$ (resp. $\left[x_{n}\right]$ ), then the proposition yields the equivalence of the six statements obtainable from the two cases. As one special case of this, we have the following result due to Milman [12]: If $\left(x_{n}, f_{n}\right)$ is complemented (in $E$ ) in the natural way (i.e. $u \rightarrow$ $\left.\Sigma f_{n}(u) x_{n}\right)$ if and only if $\left[f_{n}\right]$ norms $\left[x_{n}\right]$. It also follows that question 3 of $\S 1$ has this affirmative solution when $\left(x_{n}, f_{n}\right)$ is a bibasic system: If $\left[f_{n}\right]$ norms $\left[x_{n}\right]$, then $\left(x_{n}\right)$ is shrinking (resp. boundedly complete) if and only if $\left(f_{n}\right)$ is boundedly complete (resp. shrinking).

Let $\left(x_{n}\right)$ be basic, and define $V=\left\{f \in E^{*}\left|\|f\|_{n}=\left\|\left.f\right|_{\left[x_{n}+1, \ldots\right]}\right\| \rightarrow 0\right\}\right.$. If $I$ is the embedding of $\left[x_{n}\right]$ into $E$, then $I^{*}(V)$ is the span of the coefficient func.tionals in $\left[x_{n}\right]^{*}$.

Theorem 3. Let $\left(x_{n}\right)$ be a basic sequence in a Banach space E. Then for any $\left(f_{n}\right)$ in $E^{*}$ such that $\left(x_{n} ; f_{n}\right)$ is biorthogonal, $\overline{\left[x_{n}\right]^{\perp}+\left[f_{n}\right]}=V$, and $V$ norms E.

Proof. It is clear that $V$ is closed. Let $f$ be an element in $V$. Define

$$
g_{n}=\sum_{i=1}^{n} f\left(x_{i}\right) f_{i} \text { for all } n=1,2, \cdots
$$

Then $g_{n}$ is in $\left[f_{n}\right]$ for all $n=1,2, \cdots$ and $\left\|I^{*} g_{n}-I^{*} f\right\| \rightarrow 0$ as $n \rightarrow \infty$. Since $\left.\left\|I^{*} g_{n}-I^{*} f\right\|=\inf _{b \in\left[x_{n}\right.}\right]^{\perp}\left\|g_{n}-f+b\right\|$, choose $b_{n} \in\left[x_{n}\right]^{\perp}$ such that $\left\|g_{n}-f+b_{n}\right\|$ $\leq\left\|I^{*} g_{n}-I^{*} f\right\|+1 / n$ for each $n=1,2, \cdots$. Thus $f \in \overline{\left[x_{n}\right]^{\perp}+\left[f_{n}\right]}$.

To see that $V$ norms $E$, let $x_{n}^{*} \in\left[x_{n}\right]^{*}$ such that $\left(x_{n} ; x_{n}^{*}\right)$ is biorthogonal, and $\lambda>0$ be the characteristic of $\left[x_{n}^{*}\right]$. Define $|x|_{V}=\sup \{|f(x)|: f \in V,\|f\|=1\}$ for $x$ in $E$. We claim that $|x|_{V} \geq \lambda / 4$ for all $\|x\|=1$ in $E$.

( $\overline{\text { Case a) }} d\left(x,\left[x_{n}\right]\right) \geq \lambda / 4$.

By Hahn-Banach theorem, there exists $f$ in $E^{*}$ such that $\|f\|=1, f \in\left[x_{n}\right]^{\perp}$ and $f(x) \geq \lambda / 4$. Then $f \in V$ and $f(x) \geq \lambda / 4$. Thus $|x|_{V} \geq \lambda / 4$.

(Case b) $d\left(x,\left[x_{n}\right]\right)<\lambda / 4$.

Let $y \in\left[x_{n}\right]$ such that $\|x-y\|<\lambda / 4$. Let $x^{*} \in\left[x_{n}^{*}\right]$ such that $\left\|x^{*}\right\|=1$ and $x^{*}(y) \geq \lambda\|y\|$. Let $f$ be any extension of $x^{*}$ in $E^{*}$ with $\|f\|=1$. Then $f \in V$ and $f(x)=f(y)+f(x-y) \geq \lambda\|y\|-\|x-y\|>\lambda(\|x\|-\|x-y\|)-\lambda / 4>\lambda(1-\lambda / 4)-$ $\lambda / 4>\lambda / 2$.

Remark 4. Using Theorem 3, one makes the following observations. If $\left(x_{n}\right)$ 
is a shrinking basic sequence in $E$ and if $\left(f_{n}\right)$ is any sequence of coefficient functionals in $E^{*}$, then $\left[x_{n}\right]^{\perp} \cap\left[f_{n}\right]=\{0\}$. If, further, $\left[x_{n}\right]$ norms $\left[f_{n}\right],\left[f_{n}\right]+$ $\left[x_{n}\right]^{\perp}$ is a direct sum decomposition of $E^{*}$. Next, if $\left[x_{n}\right]$ norms $\left[f_{n}\right]$ and $\left(x_{n}\right)$ is boundedly complete, $\left(f_{n}\right)$ is shrinking so that $\left[x_{n}\right]+\left[f_{n}\right]^{\perp}$ is a direct sum decomposition of $E^{* *}$. In fact, this decomposition of $E^{* *}$ is equivalent to the boundedly-completenes $s$ of $\left(x_{n}\right)$.

The final result of this section also appears in [8].

Proposition 4. Let $\left(x_{n}, f_{n}\right)$ be a bibasic system. If $\left[f_{n}\right]$ is $w^{*} \cdot$ closed in $E^{*}$, then $\left(f_{n}\right)$ is boundedly complete.

Proof. Suppose $\sup _{n}\left\|\Sigma_{i=1}^{\infty} a_{i} f_{i}\right\|<\infty$. Let $f$ be a weak ${ }^{*}$ cluster point of $\Sigma^{n} a_{i} f_{i}$ in $E^{*}$. Since $\left(f_{n}\right)$ is basic and $\left[f_{n}\right]$ is weak ${ }^{*}$-closed, $f=\Sigma f\left(x_{n}\right) f_{n}$. It follows that $a_{n}=f\left(x_{n}\right)$ for all $n$.

4. On norming subspaces and norming bibasic sequences. Let $\left(x_{n}\right)$ be a basic sequence in a Banach space $E$. If $\left[x_{n}\right]$ is complemented in $E$, then it is easy to pick $\left(f_{n}\right)$ in $E^{*}$ such that $\left(x_{n} ; f_{n}\right)$ is biorthogonal, $\left(f_{n}\right)$ is basic and $\left[f_{n}\right]$ norms $\left[x_{n}\right]$.

Proposition 5. Let $\left(x_{n}\right)$ be a basic sequence in a Banach space E. If $\operatorname{Codim}_{E}\left[x_{n}\right]<+\infty$, then $\left[f_{n}\right]$ norms $\left[x_{n}\right]$ for any $\left(f_{n}\right)$ in $E^{*}$ such that $\left(x_{n} ; f_{n}\right)$ is biorthogonal.

Proof. Let $G$ be a finite dimensional subspace in $E$ such that $E=\left[x_{n}\right] \oplus G$. Let $P$ be the continuous projection from $E$ onto $\left[x_{n}\right]$ such that $P(G)=0$. Then $P^{*}$ is a projection from $E^{*}$ onto $G^{\perp}$ which we identify with $\left[x_{n}\right]^{*}$. Let $P^{*} f_{n}=$ $g_{n}$ for all $n=1,2, \ldots .\left[g_{n}\right]$ is the coefficient space of $\left[x_{n}\right]$ in $\left[x_{n}\right]^{*}$ and thus $\left[g_{n}\right]$ norms $\left[x_{n}\right]$. We consider two cases:

(a) $\left[x_{n}\right] \perp \cap\left[f_{n}\right]=0$.

Then since $\left[x_{n}\right]^{\perp}$ is finite dimensional, $\left[x_{n}\right]^{\perp}+\left[f_{n}\right]$ is closed and the result follows from Theorem 2 .

(b) $\left[x_{n}\right]^{\perp} \cap\left[f_{n}\right] \neq\{0\}$.

Since $\left[x_{n}\right]^{\perp}$ is finite dimensional, $\left[x_{n}\right]^{\perp} \cap\left[f_{n}\right]$ is finite dimensional. Let $F$ be a closed subspace in $E^{*}$ such that $\left[f_{n}\right]=F \oplus\left(\left\lfloor x_{n}\right]^{\perp} \cap\left[f_{n}\right]\right) . P^{*}(F)$ is total over $\left[x_{n}\right]$ and is a subspace of finite codimension in $\left[g_{n}\right]$ which norms $\left[x_{n}\right]$. Thus $P^{*}(F)$ norms $\left[x_{n}\right]$. Now $F \cap\left[x_{n}\right]^{\perp}=\{0\}$ and, so by case (a), $F$ norms $\left[x_{n}\right]$. Hence $\left[f_{n}\right]$ norms $\left[x_{n}\right]$.

In [10], Karlin showed that, for a basic sequence $\left(x_{n}\right)$ in a Banach space $E,\left[x_{n}\right]$ is complemented in $E$ if and only if coefficient functionals $\left(f_{n}\right)$ can be chosen so that $\Sigma f_{n}(u) x_{n}$ converges for every $u$ in $E$. It is clear that the bibasic system $\left(x_{n} ; f_{n}\right)$ so obtained will be a bounded norming system. The 
following result shows that a partial converse to this last statement is possible.

Theorem 4. Let $\left(x_{n} ; f_{n}\right)$ be a biorthogonal system in a Banach space $E$ with $\left(f_{n}\right)$ basic. For each $n=1,2, \cdots$, define $S_{n}(x)=\Sigma_{i=1}^{\infty} f_{i}(x) x_{i}$ for all $x$ in $E$. If $\left[f_{n}\right]$ norms $\left[x_{n}\right]$, then $\left\{S_{n}\right\}$ is uniformly bounded on $E$.

Conversely, if $\left(x_{n} ; f_{n}\right)$ is a biorthogonal system on $E$ such that $\left\{S_{n}\right\}$ is uniformly bounded on $E$, then $\left(x_{n} ; f_{n}\right)$ is bibasic and $\left[f_{n}\right]$ norms $\left[x_{n}\right]$.

Proof. For each $n=1,2, \cdots$, define $R_{n}: E \rightarrow\left[f_{1}, \cdots, f_{n}\right]^{*}$ by $R_{n}(x)=$ $\sum_{i=1}^{n} f_{i}(x) \bar{x}_{i}$ for each $x$ in $E$ where $\bar{x}_{i}=\left.x_{i}\right|_{\left[f_{1}, \ldots, f_{n}\right]}$.

Let $I_{n}:\left[f_{1}, \cdots, f_{n}\right] \rightarrow E^{*}$ be the embedding. Then $\left\|I_{n}\right\|=1$, and $R_{n}=\left.I_{n}^{*}\right|_{E}$. Hence $\left\|R_{n}\right\|=\left\|\left.I_{n}^{*}\right|_{E}\right\| \leq\left\|I_{n}^{*}\right\|=1$ for each $n=1,2, \cdots$.

Define $T_{n}:\left[f_{1}, \cdots, f_{n}\right]^{*} \rightarrow E$ by $T_{n}\left(\sum_{i=1}^{n} a_{i} \bar{x}_{i}\right)=\sum_{i=1}^{n} a_{i} x_{i}$. Then $S_{n}=T_{n} \circ R_{n}$. To show that $\left\{S_{n}\right\}$ is uniformly bounded, it suffices to show that $\left\{T_{n}\right\}$ is uniformly bounded.

Since $\left[f_{n}\right]$ norms $\left[x_{n}\right]$, let $\lambda>0$ be the characteristic of $\left[f_{n}\right]$ over $\left[x_{n}\right]$. Given $x$ in $\left[x_{1}, \cdots, x_{n}\right]$ with $\|x\|=1$, let $f=\Sigma_{i=1}^{m} a_{i} f_{i}$ in span $\left(f_{n}\right)$ such that $\|f\|=1$ and $f(x)>\lambda / 2$. Let $K$ be the basis constant of $\left(f_{n}\right)$ and $g=$ $\sum_{i=1}^{n} a_{i} f_{i}$. Then $\|g\| \leq K$ and $g(x)=f(x)>\lambda / 2$. Hence $\left(T_{n}^{-1} x\right)(g)=g(x)>$ $\lambda / 2$ and $\|g\| \leq K$. Thus $\inf _{n}\left\|T_{n}^{-1}\right\| \geq \lambda / 2 K$ and so $\sup _{n}\left\|T_{n}\right\|<\infty$.

Conversely, let $\left(x_{n} ; f_{n}\right)$ be biorthogonal and $\left\|S_{n}\right\| \leq K$ for all $n=1,2, \cdots$. Clearly, $\left(x_{n}\right)$ is basic with basis constant less than or equal to $K$.

Now $S_{n}^{n} f(x)=f\left(\sum_{i=1}^{n} f_{i}(x) x_{i}\right)=\left(\sum_{i=1}^{n} f\left(x_{i}\right) f_{i}\right)(x)$, so that $S_{n}^{*} f=$ $\sum_{i=1}^{n} f\left(x_{i}\right) f_{i},\left\|S_{n}^{*}\right\| \leq K$, and so, as $S_{n}^{*} S_{m}^{*}=S_{m}^{*} S_{n}^{*}=S_{\min (m, n)}^{*}$, we have that $\left(f_{n}\right)$ is basic.

Let $x \in\left[x_{n}\right],\|x\|=1,\left\|\Sigma_{i=1}^{n} f_{i}(x) x_{i}-x\right\|<\epsilon$. Then if $\|f\|=1, f(x)>1-\epsilon$, one has

$$
\left|f\left(\sum_{i=1}^{n} f_{i}(x) x_{i}\right)-f(x)\right|=\left|\left(\sum_{i=1}^{n} f\left(x_{i}\right) f_{i}\right)(x)-f(x)\right|<\epsilon,
$$

and $\left|\left(\sum_{i=1}^{n} f\left(x_{i}\right) f_{i}\right)(x)\right|=\left|S_{n}^{*} f(x)\right| \leq\left\|S_{n}^{*} f\right\| \leq K$ and $\left|\left(\sum_{i=1}^{n} f\left(x_{i}\right) f_{i}\right)(x)\right|>$ $1-2 \epsilon$. Hence $\sup \left\{|g(x)|:\|g\| \leq K, g \in\left[f_{n}\right]\right\} \geq 1$. Hence $\sup \{\mid g(x):\|g\| \leq$ $\left.1, g \in\left[f_{n}\right]\right\} \geq 1 / K$. Thus $\left[f_{n}\right]$ norms $\left[x_{n}\right]$.

Remark 5. Let $E$ be an infinite dimensional Banach space and let $k_{n}=$ $\sum_{1}^{n} j=n(n+1) / 2$. Using a result of Dvoretzky [5] and the technique of proof of Theorem 1 one may construct subspaces $E_{n}$ in $E$ with the following properties. Each $E_{n}$ is $\epsilon$-isometric to $l_{2, n+1}$. If $\left\{x_{k_{n+1}}, \cdots, x_{k_{n+1}}\right\}$ denotes the basis of $E_{n}$ corresponding to the usual basis of $l_{2, n+1}$ under the $\epsilon$-isometry then the natural projection of $E_{1} \oplus \cdots \oplus E_{n}$ onto $E_{m} \oplus \cdots \oplus E_{n}$ has norm no greater than 3 and so the natural projection of $\left[x_{1}, \ldots, x_{r_{n+1}} 1\right.$ onto $\left[x_{j}, \ldots, x_{r_{n+1}}\right]$ 
has norm no greater than $3(1+\epsilon)$. Thus $\left(f_{n}\right)$ may be constructed biorthogonal to $\left(x_{n}\right)$ such that $\left\|x_{n}\right\|\left\|f_{n}\right\| \leq 6(1+\epsilon)^{2}$.

If $\left[f_{n}\right]$ norms $\left[x_{n}\right]$ then the projections $S_{k_{n+1}}-S_{k_{n}}$ are uniformly bounded projections from $E$ onto $E_{n}$. In this case each space $F_{n}=\left[f_{k_{n}+1}, \cdots, f_{k_{n+1}}\right]$ is $\delta$-isometric to $l_{2, n+1}$ with $\delta$ independent of $n$.

Conversely, if $\left(x_{n} ; f_{n}\right)$ exists such that $E_{n}$ and $F_{n}$ are $k$-isometric to $l_{2, n+1}$ in the natural way then the projections

$$
f_{n}(x)=\sum_{i=k_{n}+1}^{k_{n+1}} f_{i}(x) x_{i}
$$

are uniformly bounded from $E$ onto $E_{n+1}$. To see this consider the mappings $X \stackrel{R_{n}}{\longrightarrow} F^{*} \stackrel{T_{n}^{*}}{\longrightarrow} l_{2}^{n+1} \stackrel{S_{n}}{\longrightarrow} E_{n}$ where $R_{n} \times(f)=f(x)$ for every $x$ in $X, f$ in $F_{n}$; and $T_{n}$ and $S_{n}$ are the $\epsilon$-isometries of $l_{2}^{n+1}$ with $F_{n}$ and $E_{n}$ respectively such that $f_{i}=T e_{i}, x_{i}=S e_{i}$ for where $\left[e_{k_{n}+1}, \cdots, e_{k_{n+1}}\right]$ is the usual basis for $l_{2, n+1}$. Then

$$
S_{n} T_{n}^{*} R_{n}(x)=\sum_{i=k_{n}+1}^{k_{n+1}} f_{i}(x) x_{n}
$$

and $\left\|S_{n} T_{n}^{*} R_{n}\right\| \leq\left\|S_{n}\right\|\left\|T_{n}\right\|\left\|R_{n}\right\| \leq(1+\epsilon)^{2}$.

Corollary 2. Let $\left(x_{n} ; f_{n}\right)$ be a bibasic system in a Banach space E. If $\left[f_{n}\right]$ norms $\left[x_{n}\right]$, then $B=\left\{f \in E^{*}: f=w^{*} \cdot \Sigma_{i=1}^{\infty} f\left(x_{i}\right) f_{i}\right\}$ is closed in $E^{*}$.

Proof. Since $\left(x_{n} ; f_{n}\right)$ is bibasic and $\left[f_{n}\right]$ norms $\left[x_{n}\right]$, thus $\left[x_{n}\right]$ norms $\left[f_{n}\right]$. For $f$ in $E^{*}$, let $S_{n}^{*} f=\sum_{i=1}^{n} f\left(x_{i}\right) f_{i}$, then $\left\{S_{n}^{*}\right\}$ is uniformly bounded on $E^{*}$ by Theorem 5 , say $\sup _{n}\left\|S_{n}^{*}\right\| \leq K$.

Given $f \in \bar{B}$, let $g_{i} \in B$ such that $\left\|g_{i}-f\right\| \rightarrow 0$ as $i \rightarrow \infty$. Then for each $x$ in $E,\left|S_{n}^{*} f(x)-f(x)\right| \leq\left|S_{n}^{*} f(x)-S_{n}^{*} g_{i}(x)\right|+\left|S_{n}^{*} g_{i}(x)-g_{i}(x)\right|+\left|g_{i}(x)-f(x)\right|$ $\leq K\|x\|\left\|f-g_{i}\right\|+\left|S_{n}^{*} g_{i}(x)-g_{i}(x)\right|+\left\|g_{i}-f\right\|\|x\|$. For large $i$, the first and third terms are small, and for fixed $i$ and large $n$, the middle term is small. Thus

$$
f=w^{*}-\lim _{n} S_{n}^{*} f=w^{*}-\sum_{i=1}^{\infty} f\left(x_{i}\right) f_{i}
$$

Theorem 5. Let $\left(x_{n} ; f_{n}\right)$ be a bibasic system in a Banach space E. If $\left[f_{n}\right]$ norms $\left[x_{n}\right]$, then there exists a projection $T$ on $E^{*}$ such that $T\left(E^{*}\right) \supset B=$ $\left\{f \in E^{*}: f=w^{*}-\Sigma_{i=1}^{\infty} f\left(x_{i}\right) f_{i}\right\}$ and the natural mapping $I^{*}$ maps $T\left(E^{*}\right)$ isomorphically onto $\left[x_{n}\right]^{*}$. Furthermore, $T^{*}$ is a projection on $E^{* *}$ such that $T^{*}\left(x^{* *}\right)=x^{* *}$ for all $x^{* *}$ in $\left[x_{n}\right]^{\perp \perp}$.

Proof. For $f$ in $E^{*}$, let $S_{n}^{*} f=\sum_{i=1}^{n} f\left(x_{i}\right) f_{i}$ for each $n=1,2, \ldots$. Then $\left\{S_{n}^{*}\right\}$ is uniformly bounded on $E^{*}$. Hence there exists a subnet $\left\{S_{n}^{*}\right\}$ and a 
continuous operator $T$ from $E^{*}$ to $E^{*}$ such that $\dot{T}=w^{*} \cdot \lim S_{n a_{a}^{*}}^{*}$.

It is clear that $T f=f$ for all $f$ in $B$. Thus $B=T(B) \subset T\left(E^{*}\right)$. Note that $T\left(E^{*}\right)$ is closed since $T$ is continuous.

Let $f \in E^{*}$ and $T(f)=g$. Then

$$
g=w^{*}-\lim S_{n a}^{*}(f)=w^{*}-\lim \sum_{i=1}^{n a} f\left(x_{i}\right) f_{i} .
$$

Hence $f\left(x_{i}\right)=g\left(x_{i}\right)$ for all $i=1,2, \ldots$. Thus $I^{*}(T f)=I^{*}(f)$. For any $x^{*} \epsilon$ $\left[x_{n}\right]^{*}$, let $f \in E^{*}$ such that $I^{*} f=x^{*}$. Then $g=T(f) \in T\left(E^{*}\right)$ and $I^{*}(f)=I^{*}(T f)$ $=I^{*}(g)=x^{*}$. Thus $I^{*}\left(T\left(E^{*}\right)\right)=\left[x_{n}\right]^{*}$. Now, if $I^{*}(g)=0$ for some $g=T(f)$ in $T\left(E^{*}\right)$, then $f\left(x_{i}\right)=g\left(x_{i}\right)=0$ for all $i=1,2, \ldots$. Hence

$$
g=w^{*}-\lim \sum_{i=1}^{n a} f\left(x_{i}\right) f_{i}=0 .
$$

This shows that $I^{*}$ is an isomorphism from $T\left(E^{*}\right)$ onto $\left[x_{n}\right]^{*}$.

Given $g=T(f)$ in $T\left(E^{*}\right)$, then $g\left(x_{i}\right)=f\left(x_{i}\right)$ for all $i=1,2, \cdots$ and so $S_{n_{a}}^{*} f=S_{n_{a}}^{*} g$ for all $a$.

$$
\begin{aligned}
T^{2}(f) & =T(T f)=T(g)=w^{*}-\lim \sum_{i=1}^{n_{\alpha}} g\left(x_{i}\right) f_{i} \\
& =w^{*}-\lim \sum_{i=1}^{n_{\alpha}} f\left(x_{i}\right) f_{i}=T(f) .
\end{aligned}
$$

Thus $T^{2}=T$ and $T$ is a projection on $E^{*}$.

Finally, let $x^{* *} \in\left[x_{n}\right]^{\perp \perp}=I^{* *}\left(\left[x_{n}\right]^{* *}\right)$, then $x^{* *}=I^{* *}\left(y^{* *}\right)$ for some $y^{* *} \in\left[x_{n}\right]^{* *}$. For any $f^{n}$ in $E^{*}$, we have $T^{*}\left(x^{* *}\right)(f)=T^{*}\left(I^{* *} y^{* *}\right)=I^{* *}\left(y^{* *}\right)$, that is, $T^{*}\left(x^{* *}\right)=x^{* *}$ for all $x^{* *}$ in $\left[x_{n}\right]^{\perp \perp}$.

Remark 6. As in the proof of Theorem 5, $\left\{S_{n}^{* *}\right\}$ has a $w^{*}$-convergent subnet converging to a projection in $E^{* *}$ onto the $w^{*}$-span of $\left[x_{n}\right]$ in $E^{* *}$. If $\left[x_{n}\right]$ is reflexive, then a subnet of $\left\{S_{n}\right\}$ will converge to a projection from $E$ onto $\left[x_{n}\right]$. In this way, it is easy to find basic sequences in certain spaces (e.g. $C([0,1])$ ) such that no biorthogonal sequence $\left(f_{n}\right)$ in $E^{*}$ will norm $\left(x_{n}\right)$.

The existence of norming bibasic systems finally does give direct sum de compositions in $E^{*}$. In fact, one will easily see that $E^{*}=F \oplus G$ with $F$ and $G$ both infinite dimensional if $E$ has a norming bibasic system $\left(x_{n} ; f_{n}\right)$ where $\operatorname{codim}_{E}\left(\left[x_{n}\right]\right)=\infty$.

5. Problem. Most of this paper has been concerned with norming bibasic systems $\left(x_{n} ; f_{n}\right)$ and the consequences of their existence in a space. The main problem left open by this work is:

Problem. Does every infinite dimensional Banach space admit a norming bibasic system? This problem is likely to be quite difficult as is indicated by the 
following considerations. First, it is a long unsolved problem whether or not each infinite dimensional Banach space $E$ contains closed infinite dimensional sub-spaces $A$ and $B$ such that $A+B$ is closed in $E$. The existence of a norming bibasic system having $\operatorname{dim}\left(\left[f_{n}\right]_{\perp}\right)=\infty$ in $E$ would give an affirmative solution to this question according to Remark 3.

Further, related to the approximation problem, it is not known whether or not an infinite dimensional Banach space $E$ contains finite dimensional subspaces $U$ of arbitrarily large dimension and complemented with uniformly bounded projections in $E$. The existence of norming bibasic systems gives an affirmative solution to this problem according to Theorem 4 above.

\section{REFERENCES}

1. M. M. Day, On the bases problem in normed spaces, Proc. Amer. Math. Soc. 13 (1962), 655-658. MR 25 \# 1435.

2. W. J. Davis and I. Singer, Boundedly complete M-bases and complemented subspaces in Banach spaces, Trans. Amer. Math. Soc. 175 (1973), 299-326.

3. D. W. Dean, I. Singer and L. Sternbach, On shrinking basic sequence in Banach, Studia Math. 40 (1971), 23-33.

4. J. Dixmier, Sur un théorème de Banach, Duke Math. J. 15 (1948), $1057-1071$. MR 10, 306.

5. A. Dvoretzky, Some results on convex bodies and Banach spaces, Proc. Internat. Sympos. Linear Spaces (Jerusalem, 1960), Jerusalem Academic Press, Jerusalem; Pergamon Press, Oxford, 1961, pp. 123-160. MR 25 \#2518.

6. B. R. Gelbaum, Notes on Banach spaces and bases, An. Acad. Brasil. Ci. 30 (1958), 29-36. MR $20 \# 5419$.

7. W. B. Johnson, Markushevich bases and duality theory, Trans. Amer. Math. Soc. 149 (1970), 171 - 177. MR 41 \#5927.

8. W. B. Johnson and H. P. Rosenthal, On $\omega^{*}$-basic sequences and their applications to Banach spaces, Studia Math. (to appear).

9. M. I. Kadec and A. Pełczyński, Basic sequences, bi-orthogonal systems and norming sets in Banach and Fréchet spaces, Studia Math. 25 (1965), 297-323. (Russian) MR 31 \#6112.

10. S. Karlin, Bases in Banach spaces, Duke Math. J. 15 (1948), 971-985. MR $10,548$.

11. B. L. Lin, On pseudo-reflexive Banach spaces, Math Ann. 159 (1965), $197-202$. MR 31 \# 2595.

12. V. D. Mil 'man, Geometric theory of Banach spaces. I. Theory of basic and minimal systems, Uspehi Mat. Nauk 25 (1970), no. 3 (153), 113 - 174 = Russian Math. Surveys 25 (1970), no. 3, 111-170. MR 43 \#6704.

13. F. J. Murray, Quasi-complements and closed projections in reflexive Banach spaces, Trans. Amer. Math. Soc. 58 (1945), 77 -95. MR 7, 124.

14. A. Pełczyński, A note on the paper of $I$. Singer "Basic sequences and reflexivity of Banach spaces", Studia Math. 21 (1961/62), 371-374. MR 26 \#156. 
15. A. Pelczyński, A proof of Eberlein-Šmulian theorem by an application of basic sequences, Bull. Acad. Polon. Sci. Sér. Sci. Math. Astronom. Phys. 12 (1964), 543- 548. MR 30 \#2317.

16. A. Pełczyński, and I. Singer, On non-equivalent bases and conditional bases in Banach spaces, Studia Math. 25 (1964/65), 5-25. MR 31 \#3831.

17. Ju. I. Petunin, Conjugate Banach spaces containing subspaces of zero characteristic, Dokl. Akad. Nauk SSSR 154 (1964), 527 - 529 = Soviet Math. Dokl. 5 (1964), 131 - 133. MR 28 \# 2425.

18. I. Singer, Basic sequences and reflexivity of Banach spaces, Studia Math. 21 (1961/62), 351 - 369. MR 26 \# 4155.

19. - On bases in quasi-reflexive Banach spaces, Rev. Math. Pures Appl. Bucarest 8 (1963), 309 - 311. MR 31 \#2599.

20. - Bases and quasi-reflexivity of Banach spaces, Math. Ann. 153 (1964), 199-209. MR 28 \#5321.

21. ——, Bases in Banach spaces. Vol. 1, Springer-Verlag, Berlin and New York, 1970.

DEPARTMENT OF MATHEMATICS, OHIO ST ATE UNIVERSITY, COLUMBUS, OHIO 43210 (Current address of William J. Davis and David W. Dean)

DEP ARTMENT OF MATHEMATICS, UNIVERSITY OF IOWA, IOWA CITY, IOWA 52240 (Current address of Bor-Luh Lin) 